\title{
Comparison of the Efficacy of Hydrogen Peroxide and Salt for Control of Fungal Infections on Brown Trout (Salmo trutta) Eggs
}

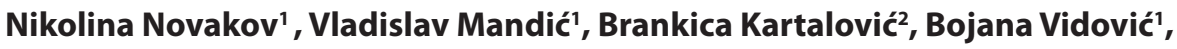 \\ Nenad Stojanac' ${ }^{1}$, Zorana Kovačević' ${ }^{\text {\& Nada Plavša' }}$
}

\begin{abstract}
Background: Fungal infections can cause serious problems infecting fish eggs, especially unfertilized or dead eggs. In the past, this problem was solved by using very effective chemicals such as malachite green and formalin. But, due to its toxicity and carcinogenicity, malachite green was banned for use in fish intended for human consumption. Formalin also has been banned in most countries. Chemicals and drugs recommended for use to treat fungal infections are hydrogen peroxide, salt, potassium permanganate etc. The goal of the present study was to determine and compare the efficacy of antifungal effects of hydrogen peroxide and sodium chloride on brown trout eggs.

Materials, Methods \& Results: The experiment was conducted in the brown trout hatchery, Šipovo, Bosnia and Herzegovina. The experimental groups contained 500 and $1,000 \mathrm{mg} / \mathrm{L}$ of hydrogen peroxide with 15 and 30 min of exposition; 1 and $2.5 \%$ of sodium chloride with 15 and $30 \mathrm{~min}$ of exposition and a negative control group (no chemical treatment). The treatment concentrations were calculated and prepared from hydrogen peroxide of $35 \%$ active ingredient, and sodium chloride (sterilized) of 100\% active ingredient. Eggs for the study were spawned from 11 females and 4 males. The first treatment was performed on the fourth day, and each next treatment was performed at 3-day intervals. Six treatments were administered until the 19th day after the fertilization. The treatment of the eggs was provided until the eggs reached the eyed stage. The effectiveness of the chemical treatments was measured by a hatch rate. There was a significant difference between all treated groups and the negative control group $(P<0.05)$. Hydrogen peroxide with a concentration of $500 \mathrm{mg} / \mathrm{L}$ for $30 \mathrm{~min}$ was the most effective and demonstrated a higher hatching rate $(75.7 \%)$. Sodium chloride treatments resulted in statistically significantly lower hatching rates than hydrogen peroxide treatments. The hatching rate in salt treatment with a concentration of $2.5 \%$ for 30 min was $27.3 \%$ lower than in hydrogen peroxide treatment with a concentration of $500 \mathrm{mg} / \mathrm{L}$ for $30 \mathrm{~min}$.

Discussion: Hydrogen peroxide is an effective antifungal, antibacterial and antiviral compound, and according to the Food and Drug Administration (FDA), hydrogen peroxide and salt are approved and classified as a low regulatory priority for the control of oomycetes on all species and life stages of fish. It is considered to be a very environmentally compatible chemical because it does not produce any toxic bioproducts when it decomposes. Hydrogen peroxide stood out as the best candidate substance for fungal control. The fact that the treatment with hydrogen peroxide at a concentration of 500 $\mathrm{mg} / \mathrm{L}$ for $30 \mathrm{~min}$ was more effective than treatments at a concentration of $1,000 \mathrm{mg} / \mathrm{L}$ can be explained by temperature dependency and treatment frequency of this chemical. Salt was not such an effective fungicide as hydrogen peroxide. When using salt, toxicity to the eggs should also be considered. Salt solutions may cause egg deaths at levels of $2.5 \%$ or higher. It is possible that high salinities have an inhibitory effect on the movement of fish embryo due to the high osmotic impact on the perivitelline layer. Thus, hydrogen peroxide has proven to be efficient, inexpensive, easy to use and environmentally safe in preventing fungal infections on brown trout eggs.
\end{abstract}

Keywords: hydrogen peroxide, sodium chloride, fungi, Saprolegnia, brown trout. 


\section{INTRODUCTION}

Fungal infections cause considerable economic problems in the fish farming industry, infecting fish and fish eggs [17]. Saprolegnia parasitica is the most important fungal pathogen for trout species [20]. Fungi attack unfertilized or dead eggs, but if left untreated they can spread over the entire egg mass and cause egg mortalities by hyphal breaching of the chorionic membrane $[12,21]$. In the past, this problem was solved by using very effective chemicals such as malachite green and formalin. The use of malachite green began in 1933 and was used extensively for many years in the absence of an authorized veterinary medicinal alternative [9]. But, due to its toxicity and carcinogenicity, malachite green was banned for use in fish intended for human consumption [19]. Formalin is a powerful disinfectant, but also has been banned in most countries [1,13]. Chemicals and drugs recommended for use to treat fungal infections in the treatment of fungal infections are hydrogen peroxide, salt, iodophores, potassium permanganate, ozone etc. [8].

In trout hatcheries in Serbia and Bosnia and Hercegovina, the usage of hydrogen peroxide and salt is the most common in the control of fungal infections. Taking in consideration that the efficacy of hydrogen peroxide can be influenced by water quality, temperature and the population level of Saprolegnia spp. [2], a treatment which works well at one location and under certain conditions may not work well at another location. The aim of the present study was to investigate the antifungal effect of hydrogen peroxide and sodium chloride on brown trout eggs, and to determine which chemical treatment regime is the most effective.

\section{MATERIALS AND METHODS}

\section{Design of the experiment and gathering data}

The present study was conducted from December 2015 until the end of February 2016, in the brown trout (Salmo trutta) hatchery on the territory of the municipality of Šipovo, Bosnia and Herzegovina. The experiment was divided into 3 trials as follows: (1) experimental group I contained 500 and $1,000 \mathrm{mg} / \mathrm{L}$ of hydrogen peroxide with 15 and 30 min of exposition; experimental group II contained 1 and $2.5 \%$ of sodium chloride with 15 and 30 min of exposition and (3) a control group (no chemical treatment). Each treatment was performed in 3 replicates, which in total scored
27 experimental groups. The treatment concentrations were calculated and prepared from hydrogen peroxide of $35 \%$ active ingredient, and sodium chloride (sterilized) of $100 \%$ active ingredient. Eggs for the study were spawned from 11 females and 4 males. The fertilized eggs were all mixed together her before they were distributed into 27 incubating cylinders of 1000 eggs each. Each incubating cylinder was supplied with water by separate drains. The first treatment was performed on the fourth day, and each next treatment was performed at three-day intervals. Six treatments were administered until the 19th day after the fertilization. The treatment of the eggs was provided until the eggs reached the eyed stage. From this stage to the hatching, the fungi were controlled by removing the infected eggs. The dead eggs were removed and counted. The effectiveness of the chemical treatments was measured by a hatch rate.

\section{Test condition}

The water source for the hatcheries is the Janj River, with typical mean water quality characteristics as follows: ( $\mathrm{pH} 7.5 ; 93 \%$ of dissolved $\mathrm{O}_{2} ; 492 \mu \mathrm{S} / \mathrm{cm}$ as electrical conductivity) at $7.9^{\circ} \mathrm{C}\left(5.2^{\circ} \mathrm{C}-11.4^{\circ} \mathrm{C}\right)$. The physical and chemical properties of the water were measured twice daily by a multifunctional measuring instrument Multi 340i by WTW ${ }^{1}$ in combination with an OxyGuard System².

\section{Statistical analysis}

The data analysis was carried by using Statistica $13^{3}$ software to determine the descriptive statistic parameters (mean, standard deviation). The hatching rate in different treatments was analyzed by the analysis of variance (ANOVA) and the presence of a significant difference among mean values was tested by Duncan's multiple-range test at $P<0.05$.

\section{RESULTS}

The results of the effect of hydrogen peroxide and sodium chloride at certain concentrations and exposure times on the occurrence of saprolegniosis and the hatching rate in fertilized eggs of brown trout are shown in Table 1 . The dose of $500 \mathrm{mg} / \mathrm{L}$ of hydrogen peroxide in $30 \mathrm{~min}$ treatment brought the greatest hatching ratio of $75.7 \%$. Negative control without disinfectants and removal of the infected and dead eggs after the pre-eyed stage resulted in the lowest hatching percentage of $36.4 \%$. There was a significant difference between all treated groups and negative control $(P<$ 
0.05). Also, there was a significant difference between treatments with hydrogen peroxide and treatments with sodium chloride. A concentration of $500 \mathrm{mg} / \mathrm{L}$ hydrogen peroxide during 30 min of exposition significantly differed from the treatment with $1,000 \mathrm{mg} / \mathrm{L}$ in $30 \mathrm{~min}$, $500 \mathrm{mg} / \mathrm{L}$ and $1,000 \mathrm{mg} / \mathrm{L}$ in 15 -min duration. Among the groups treated with salt, the one of $2.5 \%$ during 30 min showed the highest hatching rate (48.4\%), and was significantly different from the other salt treatments.

\section{DISCUSSION}

Hydrogen peroxide is an effective antifungal, antibacterial and antiviral compound, and according to the Food and Drug Administration (FDA), hydrogen peroxide and salt are approved and classified as a low regulatory priority for the control of oomycetes on all species and life stages of fish [1,9]. It is considered to be a very environmentally compatible chemical because it does not produce any toxic bioproducts when it decomposes [10]. There are also new strategies for controlling saprolegniosis such as the usage of bacterial antagonists, boric acid, paracetic acid, essential oils and glucans, but these substances have not yet shown satisfactory results [1]. Based on the results of this study it was expected that hydrogen peroxide would have the best results, but it was necessary to determine in which concentration and at what time of exposition it would be the most effective, especially under conditions that are present in most of the trout hatceries in Bosnia and Herzegovina and the region. Known as one of the most effective antifungal agents available for the use in trout eggs at the present time $[4,7,9,18]$, hydrogen peroxide stood out as the best candidate substance for fungal control. The obtained results are in accordance with similar studies. Kitancharoen et al. [11] concluded that 1,000 ppm hydrogen peroxide for 60 min twice a week was equally effective as 2 ppm malachite green with the same exposure durations. Hydrogen peroxide was fungicidal and non-toxic to eggs at 500 ppm for 60 min every other day, and that it is considered safe in the environment [14]. A concentration of 250-500 $\mathrm{mg} / \mathrm{L}$ hydrogen peroxide for $15 \mathrm{~min}$ could be efficient as prophylactic treatment for eggs [5]. The most similar results with this were obtained in the study of Hansen [9], where 500 ppm for 15 min treatment was slightly more effective than other hydrogen peroxide treatments. The fact that the treatment with hydrogen peroxide at a concentration of $500 \mathrm{mg} / \mathrm{L}$ for $30 \mathrm{~min}$ was more effective than treatments at a concentration of $1,000 \mathrm{mg} / \mathrm{L}$ can be explained by temperature dependency and treatment frequency of this chemical $[3,10]$. Gaikowsky et al. [7] found a significant decrease in the probability of hatch related to hydrogen peroxide treatment, and a treatment with 1,000 ppm for $15 \mathrm{~min}$ 5 times a week gave $7 \%$ less hatch rate than the same exposure durations with $500 \mathrm{ppm}$. In the present study, the hatching rates of $1,000 \mathrm{mg} / \mathrm{L}$ for 30 and $15 \mathrm{~min}$ were $6.4 \%$ and $1.9 \%$ respectively lower than those for $500 \mathrm{ppm}$ for $15 \mathrm{~min}$.

Sodium chloride treatments resulted in statistically significantly lower hatching rates than hydrogen peroxide treatments. The hatching rate in the hydrogen peroxide treatment of $500 \mathrm{mg} / \mathrm{L}$ for $30 \mathrm{~min}$ was $27.3 \%$ higher than in the salt treatment with $2.5 \%$ for $30 \mathrm{~min}$. This is expected because salt is not such an effective fungicide as hydrogen peroxide. When using

Table 1. Results from the hydrogen peroxide and sodium chloride treatments of brown trout eggs.

\begin{tabular}{|c|c|c|c|c|c|}
\hline \multicolumn{4}{|c|}{ Treatment } & \multicolumn{2}{|c|}{ Hatching rate } \\
\hline Substance & Time/min & Concentration & $\mathrm{N}^{*}$ & $X^{* *}$ & $\mathrm{SD}^{* * *}$ \\
\hline \multirow{4}{*}{ Hydrogen peroxide } & \multirow{2}{*}{15} & $500 \mathrm{mg} / \mathrm{L}$ & 3 & $71.2^{\mathrm{a}}$ & 2.5 \\
\hline & & $1,000 \mathrm{mg} / \mathrm{L}$ & 3 & $69.3^{\mathrm{a}}$ & 1.4 \\
\hline & \multirow{2}{*}{30} & $500 \mathrm{mg} / \mathrm{L}$ & 3 & $75.7^{\mathrm{b}}$ & 1.6 \\
\hline & & $1,000 \mathrm{mg} / \mathrm{L}$ & 3 & $69.9^{a}$ & 1.5 \\
\hline \multirow{4}{*}{ Sodium chloride } & \multirow{2}{*}{15} & $1 \%$ & 3 & $40.3^{c}$ & 0.9 \\
\hline & & $2.5 \%$ & 3 & $45.4^{\mathrm{d}}$ & 1.0 \\
\hline & \multirow{2}{*}{30} & $1 \%$ & 3 & $40.9^{c}$ & 0.4 \\
\hline & & $2.5 \%$ & 3 & $48.4^{\mathrm{e}}$ & 0.9 \\
\hline Negative control & - & - & 3 & $36.4^{\mathrm{f}}$ & 1.2 \\
\hline
\end{tabular}


salt, toxicity to the eggs should also be considered. Salt solutions may cause egg deaths at levels of $2.5 \%$ or higher [6]. It is possible that high salinities have an inhibitory effect on the movement of fish embryo due to the high osmotic impact on the perivitelline layer [15]. In the study conducted by Hansen [9], the results with the salt usage were similar with the results obtained here and a concentration of $20 \mathrm{ppt}$ for $30 \mathrm{~min}$ resulted in a hatching rate of $44.3 \%$, which was also the case in the study by Kitancharoen et al. [11], which used a $2.5 \%$ salt solution to treat the rainbow trout eggs twice a week for $60 \mathrm{~min}$ and obtained a hatching rate of $46 \%$.

\section{CONCLUSION}

The general conclusion is that hydrogen peroxide is very effective for fungal control in the case of all exposure durations and concentrations used in the present study, especially at $500 \mathrm{mg} / \mathrm{L}$ for $30 \mathrm{~min}$. It is definitely better than salt and negative control and as a liquid it is easy to work with. The results obtained for the salt usage in the control of fungal infections on brown trout eggs indicates that this substance is better than negative control but it is not effective enough and cannot be recommended for usage.

\section{MANUFACTURERS}

${ }^{1}$ WTW GmbH. Weilheim, Germany.

${ }^{2}$ OxyGuard International A/S. Farum, Denmark.

${ }^{3}$ Dell Statistica. Tulsa, OK, USA.

Funding. This study was supported by the Ministry of Education, Science and Technological Development, Republic of Serbia [grant number TR 31011/2011-2018].

Declaration of interest. The authors report no conflicts of interest. The authors alone are responsible for the content and writing of paper.

\section{REFERENCES}

1 Ali S.E., Evensen Ø. \& Skaar I. 2015. Recent advances in the mitigation of Saprolegnia infections in freshwater fish and their eggs. In: Méndez-Vilas A. (Ed). The Battle Against Microbial Pathogens: Basic Science, Technological Advances and Educational Programs. Badajoz: Formatex Research Center, pp.691-697.

2 Barnes M.E., Ewing D.E., Cordes R.J. \& Young G.L 1998. Observations on hydrogen peroxide control of Saprolegnia spp. during rainbow trout egg incubation. The Progressive Fish-Culturist. 60: 67-70.

3 Bovbjerg Pedersen P., Sortkjær O., Steenfeldt S. \& Aarup P. 2000. Hydrogen peroxid, $\mathrm{H}_{2} \mathrm{O}_{2}$. In: Sortkjær O. (Ed). Unders $\phi$ gelse af eventuelle miljфpavirkninger ved anvendelse af hjolpestoffer og medicin i ferskvandsdambrug samt metoder til at reducere/eliminere sadanne pavirkninger. Danmarks Fiskeriundersøgelser. DFU-Report 79-00. Denmark. pp.95-109.

4 Bruno D.W., Van West P. \& Beakes G.W. 2011. Saprolegnia and other oomycetes. In: Woo P.T.K. \& Bruno D.W. (Eds). Fish Diseases and Disorders: Viral, Bacterial and Fungal Infections. v.3. 2nd edn. Wallingford: CABI International, pp.669-720.

5 Dawson V.K., Rach J.J. \& Schreier T.M. 1994. Hydrogen peroxide as a fungicide for fish culture. Bulletin of the Aquaculture Association of Canada. 2: 54-56.

6 Edgell P., Lawseth D., Mclean W.E. \& Britton E.W. 1993. The use of salt solutions to control fungus (Saprolegnia) infestations on salmon eggs. The Progressive Fish-Culturist. 55: 45-52.

7 Gaikowski M.P., Rach J.R., Olson J.J., Ramsay R.T. \& Wolgamood M. 1998. Toxicity of hydrogen peroxide treatments to rainbow trout eggs. Journal of Aquatic Animal Health. 10: 241-251.

8 Hanjavanit C., Panchai K., Kitancharoen N. \& Hatai K. 2013. The anti-oomycetic effects of sodium chloride and potassium permanganate and the toxicity of these compounds to tilapia (Oreochromis niloticus) eggs. African Journal of Microbiology Research. 7(18): 1852-1857.

9 Hansen E.P.E. 2004. Prevention of Saprolegnia on rainbow trout eggs. 50p. BSc. Thesis, University of the Faroe Island, Denmark.

10 Hjelme U. 2000. BioCare SPC - Et oxiderende desinfektionsmiddel baseret pa natriumpercarbonat. In: BioMar. BioCare SPC 2000. Special edition. Brande: BioMar, 2p.

11 Kitancharoen N., Yamamoto A. \& Hatai K. 1998. Effects of sodium chloride, hydrogen peroxide and malachite green on fungal infection in rainbow trout eggs. Biocontrol Science. 3(2): 113-115.

12 Liu Y., De Bruijn I., Jack A.L., Drynan K., Van Den Berg A.H., Thoen E., Sandoval-Sierra V., Skaar I., Van West P., Diéguez-Uribeondo J., Van Der Voort M., Mendes R., Mazzola M. \& Raaijmakers J.M. 2014. Deciphering microbial landscapes of fish eggs to mitigate emerging diseases. The ISME Journal. 8(10): 2002-2014 
13 Magaraggia M., Faccenda F., Gandolfi A. \& Jori G. 2006. Treatment of microbiologically polluted aquaculture waters by a novel photochemical technique of potentially low environmental impact. Journal of Environmental Monitoring. 8: 923-931.

14 Marking L.L., Rach J. \& Schreier T.M. 1994. Search for antifungal agents in fish culture. In: Mueller G.J. (Ed). Salmon saprolegniasis. Portland: Bonneville Power Administration, pp.131-148.

15 Martinez-Palacios C.A., Morte J.C., Tello-Ballinas J.A., Toledo-Cuevas M. \& Ross L.G. 2004. The effects of saline environments on survival and growth of eggs and larvae of Chirostoma ester ester Jordan 1880 (Pisces: Atherinidae). Aquaculture. 238: 509-522.

16 Pottinger T.G. \& Day J.G. 1999. A Saprolegnia parasitica challenge system for rainbow trout: assessment of Pyceze as an anti-fungal control agent for both fish and ova. Diseases of Aquatic Organisms. 36: 129-141.

17 Rach J.J., Schreier T., Gaikowski M.P. \& Schleis S.M. 2005. Efficacy of formalin and hydrogen peroxide to increase survival of channel catfish infected with saprolegniasis. Northern American Journal of Aquaculture. 67: 312-318.

18 Schreier T.M., Rach J.J. \& Howe G.E. 1996. Efficacy of formalin, hydrogen peroxide, and sodium chloride on fungal-infected rainbow trout eggs. Aquaculture. 140: 323-331.

19 Srivastava S., Sinha R. \& Roy D. 2004. Toxicological effects of malachite green. Aquatic Toxicology. 66: $319-329$.

20 Torto-Alalibo T., Tian M.Y., Gajendran K., Waugh M.E., Van Wes V. \& Kamoun S. 2005. Expressed sequence tags from the oomycete fish pathogen Saprolegnia parasitica reveal putative virulence factors. BMC Microbiology. 5: 46.

21 Wyatt T. \& Barkoh A. 2003. Investigation of formalin and hydrogen peroxide treatments to control fungus on Florida Largemouth Bass eggs. Management Data Series No. 216. Austin: Inland Fisheries Division, pp.1-16. 